\title{
Design and Simulation of IoT and Zigbee based Smart Lighting System
}

\author{
Bevek Subba $^{1}$, Choki Wangchuk ${ }^{1}$, Seema Ghalley ${ }^{1}$, Jigmi ${ }^{1}$, Lhendup Jamtsho ${ }^{1}$, Sangay Chedup ${ }^{1}$ \\ Department of Electronics and Communication Engineering, Jigme Namgyel Engineering College, Dewathang, Bhutan ${ }^{1}$
}

\begin{abstract}
With the advancement of technology in the field of Internet of Things (IoT), solid state lighting and control system, smart lighting is getting a lot of attention. The concept is constantly evolving to meet the next generation devices that work with IoT. In the modern day's residential buildings, the indoor lighting accounts for $15-20 \%$ of the total energy consumption. The aim of the project is designing of low-cost embedded systems for energy saving lighting system which can provide the real time information and monitoring of the system through internet. With the help of Light Dependent Resistor (LDR) and Passive Infra-Red (PIR) sensors, the lighting of the bulb can be controlled whenever a person enters a room. This implies that the lights will remain OFF when it is not used. The system design can be possible with the help of sensors and programming micro-controllers. The sensor data can also be sent from Zigbee transmitter to Zigbee receiver through wireless channel, so that the person who is a receiver can always monitor the usage of the light. New technology such as STEMSEL (Science Technology Engineering Maths Social Enterprise Learning) development boards were also used in the project in order to infuse IoT to the system. At the end, the sensor data would be sent from the transmitter to receiver through wireless and the website would be created which can be accessed from anywhere through internet. A case study is also done in order to check the energy efficiency of the system.
\end{abstract}

Keywords: IoT, LDR, PIR, Zigbee, STEMSEL, Smart Lighting.

\section{INTRODUCTION}

Energy being the most essential thing that drives the modern world has had immense impact as to how the world uses these energies sustainable. The most utilized energy is the electricity which seems to be gradually degrading especially the one which is produced from non-renewable resources. So arguably, the amount of energy that is saved is very important. Energy can be saved with every little action, as energy efficiency is what the whole world thriving for in this current phase of the world. In order to promote sustainable energy, focus need to be given on energy efficiency and renewable energy. Many countries have enforced policies that the energy efficiency is the best national security benefit as this strategy can be used to reduce the total energy usage and hence reduce energy imports as well as reduce depletion of energy resources. In today's residential buildings, the indoor lighting accounts for 15-20\% of the total energy consumption [1]. So, this project is mainly designed and executed for the development of embedded systems for energy saving lighting system which can provide the real time information of the system through internet. There are many ways to reduce energy consumption but lighting control proved to be the most efficient way to reduce energy consumption and wastage of energy.

Smart lighting is the lighting technology designed for energy efficiency, convenience and security which is also the first step towards automated IoT technology. Smart lighting uses intelligent, connected devices to make the lighting system more sustainable, responsive, efficient and secure for the users. Smart lighting may use a single bulb or an intelligent socket with necessary sensors connected, both of these are connected to a internet via Wi-Fi module which lets the user to monitor the energy consumption of the bulb. Smart lighting is one of the most convenient ways of reducing energy consumption. It enables users to remotely control the lighting and minimizing the unnecessary energy use. This technique or the strategy not only saves energy but also provides comfort and convenience to the users. Smart lighting uses a simple concept of utilizing natural light or energy efficiently by just turning off light when not in use [1-5]. This is done with the help of various sensors like PIR sensors and LDR sensors using Arduino and Stemsel. Internet of things is made up of interrelated devices and machines which has the ability to transfer information over a network without the intervention of human [3-9] The internet of things has made people live in more advanced and smarter ways. There is various type of applications of IoT devices and machines which are divided into consumer, commercial, industrial and smart home. IoT devices that are used for home automation which includes lighting, heating, security and media with the help of a hub that can control all the devices connected to it. IoT helps the users to monitor and control the overall environment that the IoT devices are used at. The IoT automated system ensures energy saving in the long run by automatically turning off lights when not in use. This paper gives the design of a automatic smart lighting system which emphasizes on saving energy. The system is affordable as well as convenient for the users. 


\section{DOI 10.17148/IARJSET.2020.7908}

\section{RELATED WORKS}

Smart street light monitoring system was designed in [4] using Xbee wireless module, LDR, microcontroller. The controller will process the data and communicates wirelessly with the control centre with the help of Xbee. With this technique, the control centre could track the lamps which are not working. The lamps could also be ON with low brightness when that particular lamp is not used. Smart LED system was utilized for industrial and domestic purpose in [5]. In [6], the street light systems were designed which automatically ON and OFF according to the situation using light sensor and photo electric sensor. The paper gives the idea of the controlling intensity of the light when the sensor detects the movement of external body. The light switches OFF in the daylight promoting energy saving.

[7] proposes an IoT based embedded system of street light that saves energy using LDR, IR sensor, UART, relay, arduino and Wifi module. The system also detects the motion. Accordingly puts ON/OFF the lights and updates the IoT page using Wifi module. In [8], GSM technology is used to put ON and OFF the light controlling the brightness. PIR sensor is also used along with LDR, for sensing of the human and Zigbee is used for communication purpose in [9]. Turning ON and OFF the street light, depend on the data received from the Zigbee module. The system runs with solar energy and battery backup. [10-12] emphasizes on home security system using Internet. The information is sent to the owner when there is an intruder in the house. The alarm will be triggered remotely from the phone.

\section{SYSTEM MODEL}

The LED bulb is used for its long lasting and energy saving advantage for lighting source [13]. PIR sensor is used for motion detection within the range of 7 meters in 120 degree [14]. It detects any human entering the room and triggers the light bulb to turn ON. LDR sensor is used for detecting lighting intensity in the room and creates such a condition that the LED Bulb will not be turned $\mathrm{ON}$ if light intensity is above certain value in the room. Zigbee is a wireless communication protocols which have a suite of specification for devices to follow so that they can transfer data over air. Two Zigbee module is used for transmitting and receiving data to transfer data from the LDR sensor through wireless. Arduino is used as a processor for processing data and codes. It is the controlling unit of the whole system.

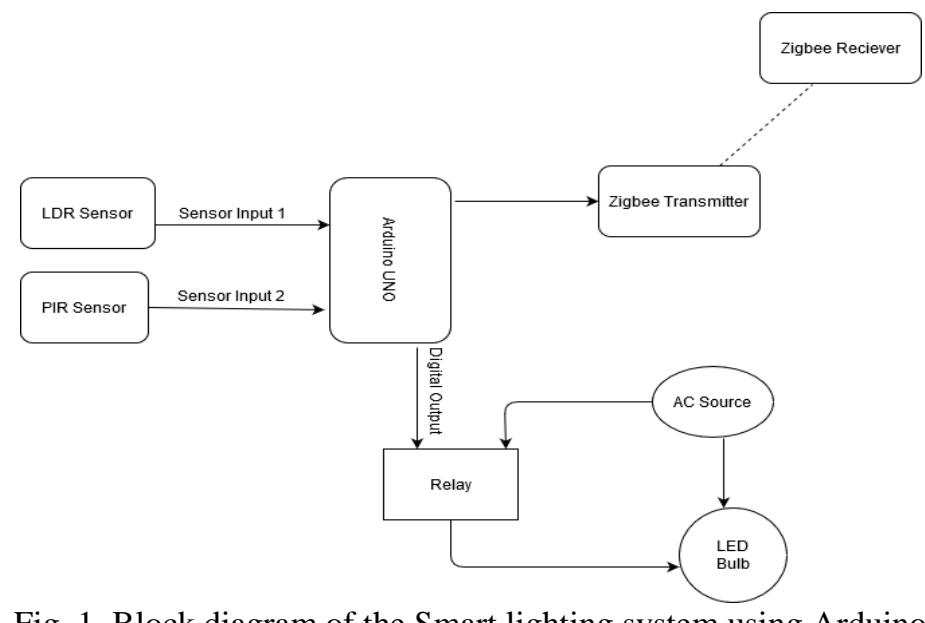

Fig. 1. Block diagram of the Smart lighting system using Arduino

The input is provided by the two sensors (i.e., LDR and PIR) to the Arduino board where all the processing take place as shown in Figure 1. The bulb will be turned on only when the LDR sensor detects the light intensity below certain level and PIR sensor detects motion. This logic is shown in the flowchart shown in Figure 3. The value received from PIR sensor and LDR sensor is transferred to the control unit (Arduino Board) where processing occurs according to the program. The bulb is Connected via 5V relay and placed on the ceiling or an overlooking corner in the room. A Zigbee module connected to the Arduino transmits the information to another Zigbee module which is a receiver [15-21]. For IoT purpose, STEMSEL Board is used to access the internet. The value received from PIR sensor and LDR sensor is transferred to the control unit (STEMSEL Board) where processing occurs according to the program. The bulb is connected via $5 \mathrm{~V}$ relay and placed on the ceiling or an overlooking corner in the room. A Wi-Fi module connected to the board, transmits the information to the runlinc webpage, which can be access from anywhere from the world. STEMSEL [22] with its Wifi module is used in order to access the webpage. The runlinc webpage allows the programming, controlling and monitoring of the ports. Figure 2 gives the block diagram of the Smart lighting system using STEMSEL. 
International Advanced Research Journal in Science, Engineering and Technology

Vol. 7, Issue 9, September 2020

DOI 10.17148/IARJSET.2020.7908

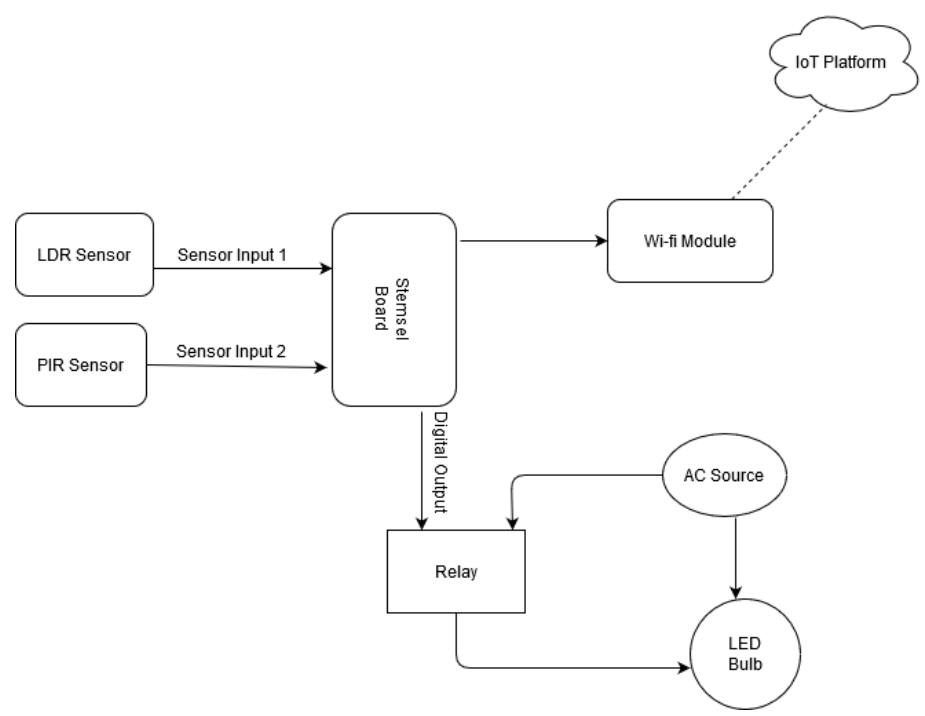

Fig. 2. Block diagram of the Smart lighting system using STEMSEL

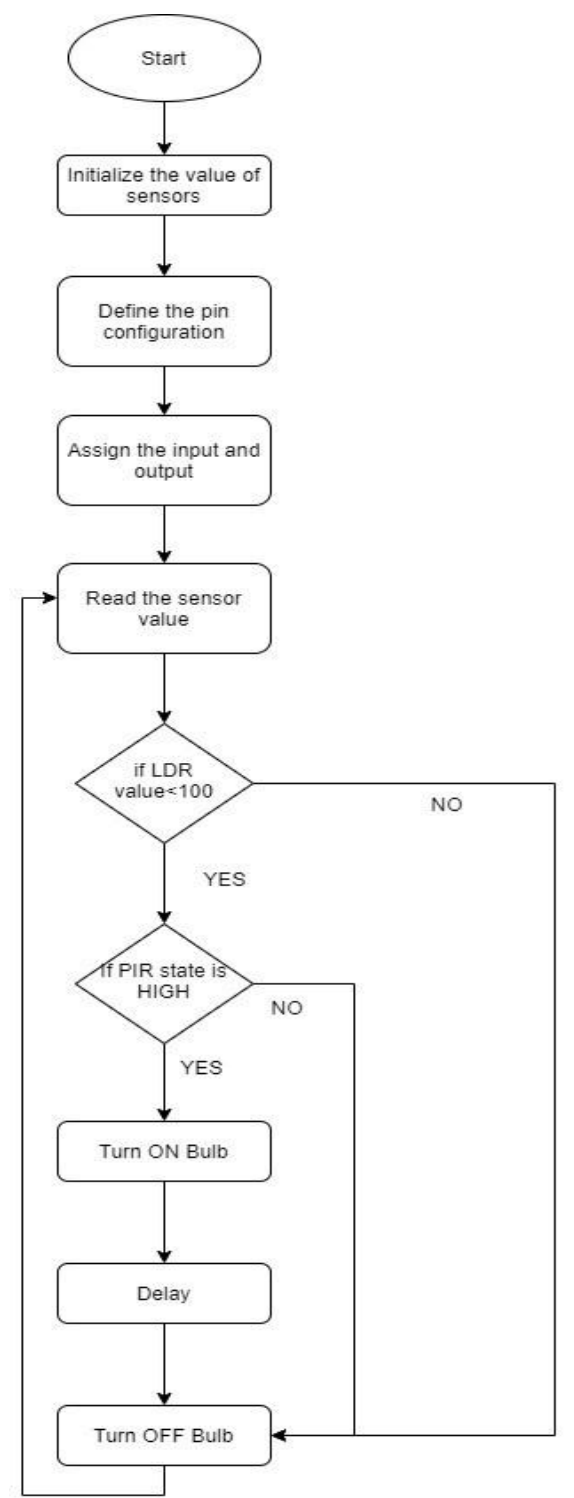

Fig. 3. Flowchart of working of the system 
International Advanced Research Journal in Science, Engineering and Technology

Vol. 7, Issue 9, September 2020

DOI 10.17148/IARJSET.2020.7908

\section{SIMULATION AND IMPLEMENTATION}

Table 1 indicates the components used in the project. The circuit was designed according to the block diagram and the simulation was done as shown in the Figure 5. The hardware connection was done with Arduino and Zigbee as shown in the Figure 6 and with the STEMSEL in the Figure 7.

TABLE 1 COMPONENTS USED IN THE PROJECT

\begin{tabular}{|c|c|c|}
\hline Sl.No. & Components & Specifications \\
\hline 1 & Arduino UNO & $5 \mathrm{~V}, 16 \mathrm{MHz}$ \\
\hline 2 & PIR Sensor & HC-SR501, 3V \\
\hline 3 & LDR Sensor & $5 \mathrm{~V}, 1 \mathrm{KOhm}$ \\
\hline 4 & LED Bulb & Philips, 12Watts \\
\hline 5 & Relay & $5 \mathrm{~V}$ \\
\hline 6 & Resistor & $1 \mathrm{KOhm}$ \\
\hline 7 & STEMSEL & V1.1 \\
\hline 8 & Zigbee Module & S2C 100m range \\
\hline 9 & Wifi module & ESP01S \\
\hline
\end{tabular}

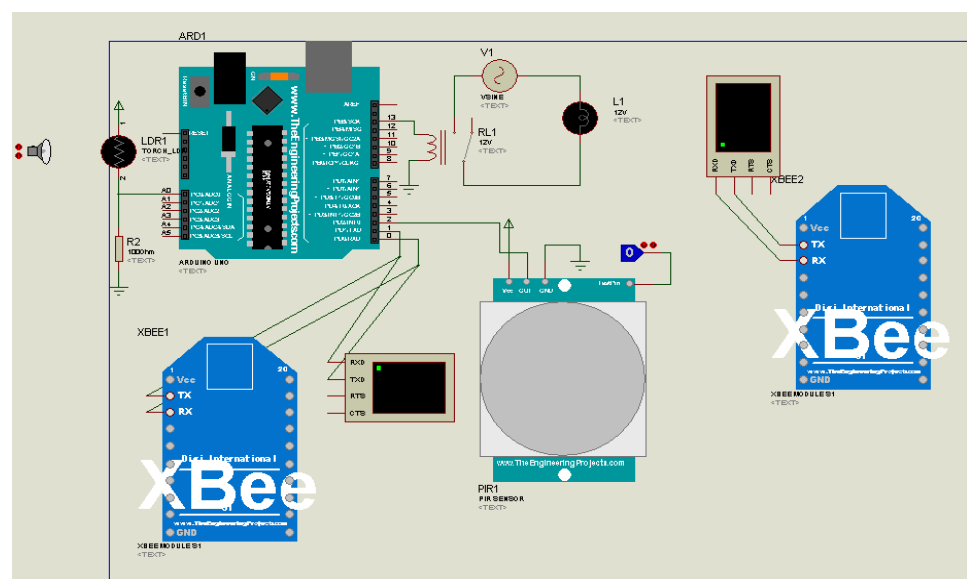

Fig. 4. Simulation of the circuit

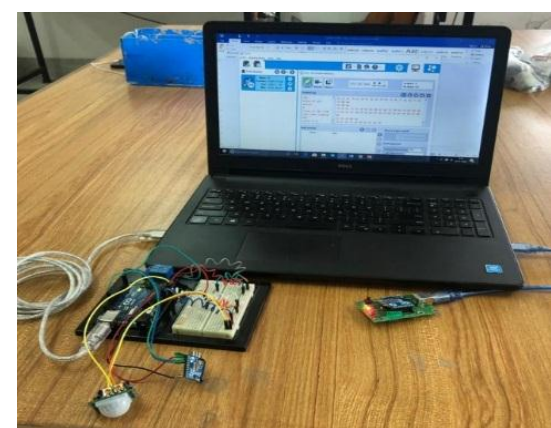

Fig. 5. Hardware connection in the laboratory with Arduino and Zigbee using XCTU

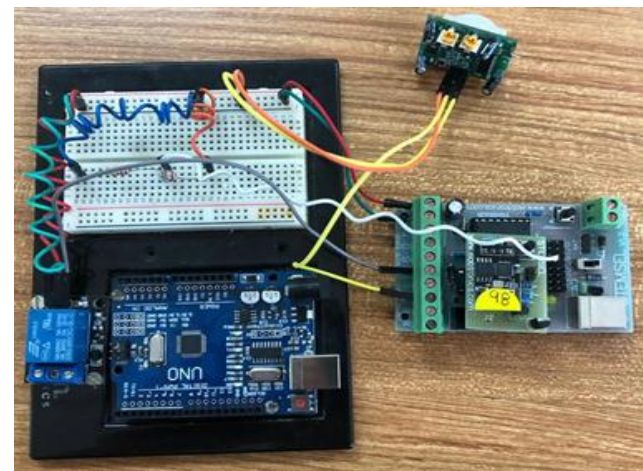

Fig. 6. Hardware connection in the laboratory with STEMSEL 


\section{International Advanced Research Journal in Science, Engineering and Technology}

Vol. 7, Issue 9, September 2020

\section{DOI 10.17148/IARJSET.2020.7908}

\section{RESULT}

5.1 Successful data sent through wireless

XCTU application is used to interact with RF modules through graphical interface. The sensor data can be accessed remotely from XCTU in the control room and the lighting can be monitored. Two Zigbee modules will be configured as transmitter and receiver with the help of XCTU. The sensor values reading are printed in the serial plotter of the Arduino, and those values are transmitted to the Zigbee module. When the sensor data are written in the Zigbee module, the other Zigbees that have same PAN ID will receive the same data. The other Zigbee receiver is connected to a PC to monitor the sensor values in real time with seconds of delay.

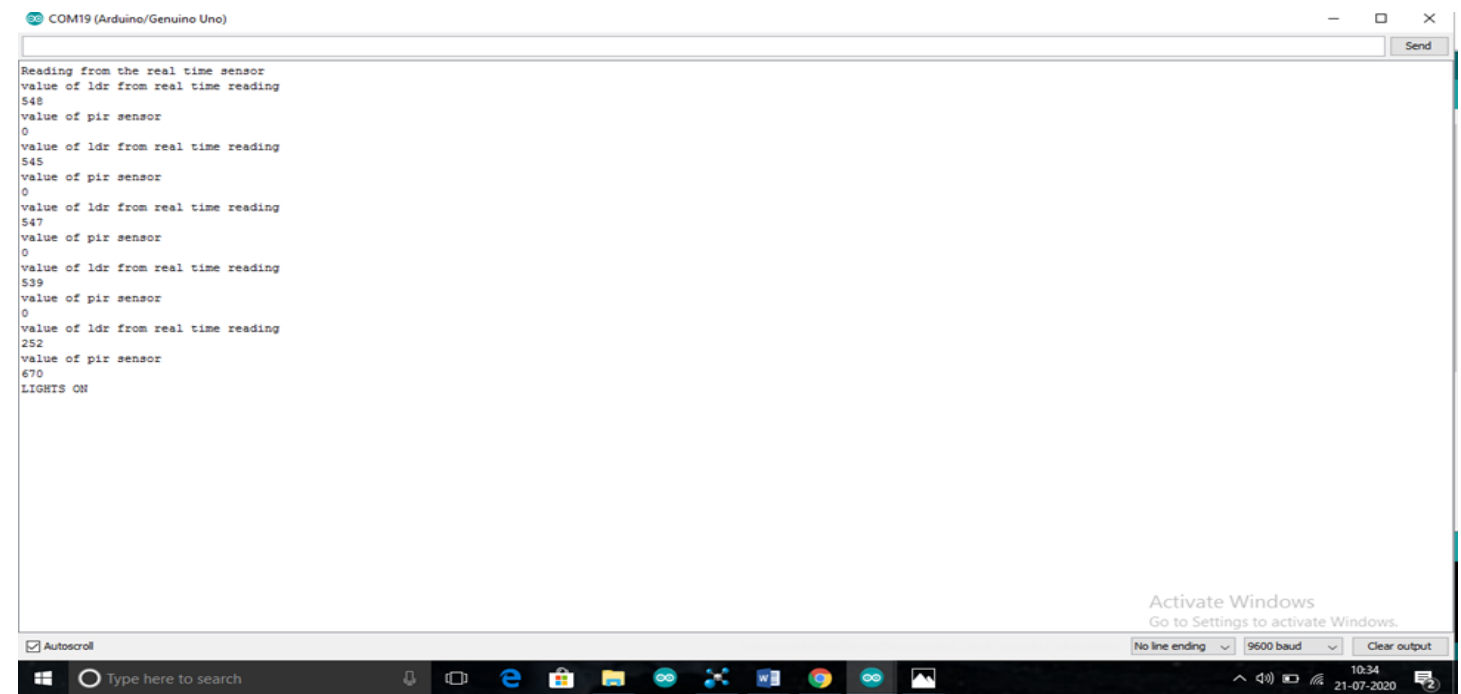

Fig. 7. Reading on Serial Monitor in Arduino software

After the sensor values are received in the coordinator Zig- Bee, the router receives the sensor values from the coordinator since they have the same PAN ID. The exact message that was displayed in the serial plotter of the coordinator side, has been displayed in the XCTU console log of the Router side.

\subsection{Runlinc Webpage creation}

runlinc is a web page inside a Wi-Fi chip. The programming is done inside the browsers compare to programming inside a chip. The runlinc web page inside the Wi-Fi chip will command the microchips to do sensing, control, data logging Internet of Things (IoT). The program was written in the runlinc and the lighting was able to be controlled smartly with the help of the sensors. The main program is written in the Java Script and Java Script Loop. HTML is used for creating the control website for the STEMSEL and CSS for decorating the website with colors. The website can be accessed by typing the IP address of the runlinc (192.168.137.98). The website can also be accessed using a mobile phone in which the lighting system can be controlled using ON and OFF button.

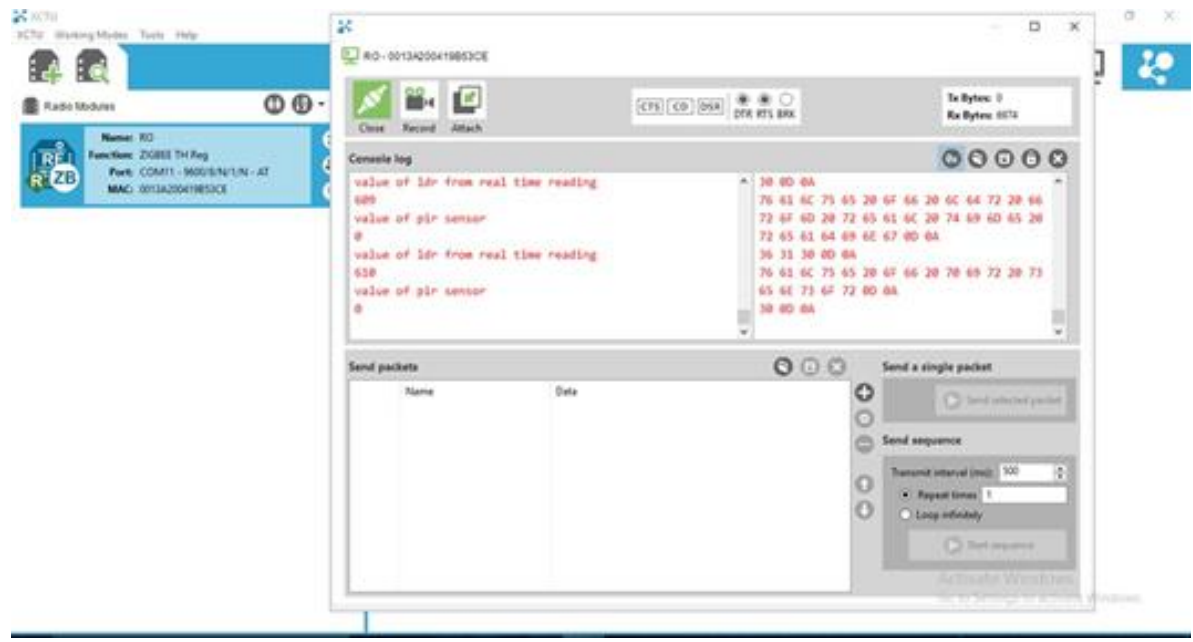

Fig. 8. LDR sensor value reading on XCTU Router side 


\section{International Advanced Research Journal in Science, Engineering and Technology}

Vol. 7, Issue 9, September 2020

\section{DOI 10.17148/IARJSET.2020.7908}

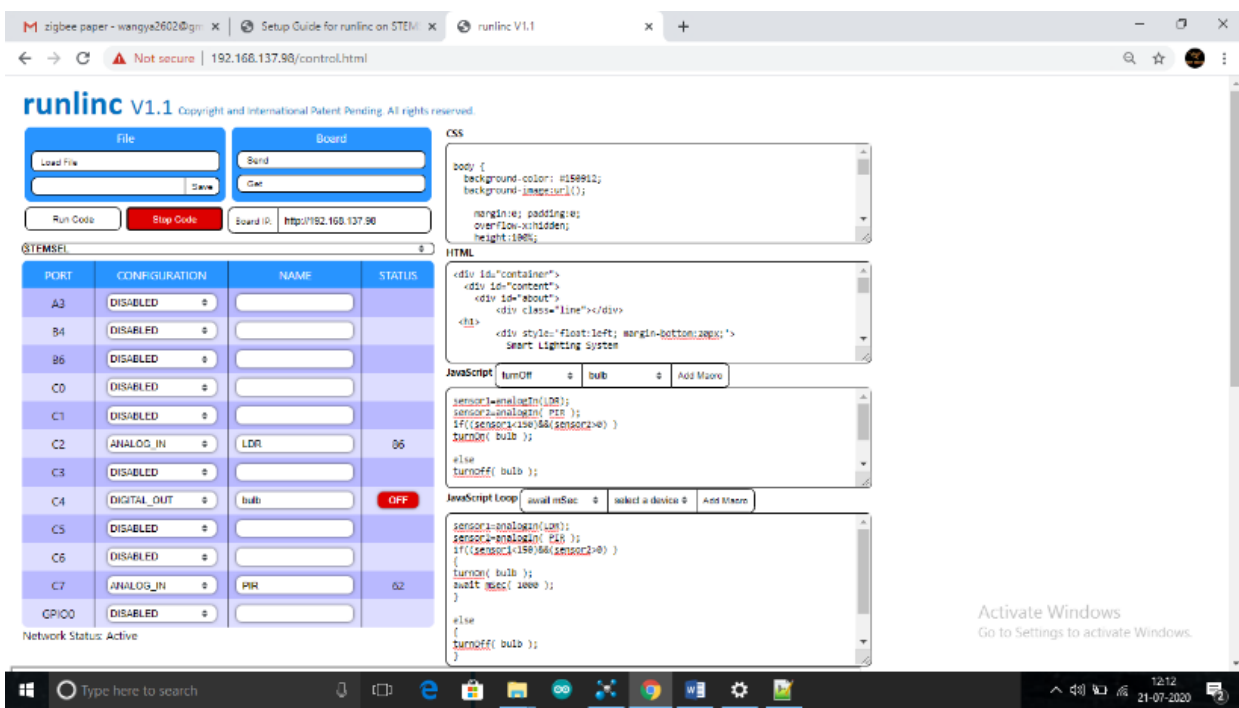

Fig. 9. runlinc webpage

\subsection{Case Study on the Energy Efficiency}

To study the energy consumption and its efficiency of existing lighting system and the smart lighting system, JNEC library washroom was chosen since it was one of the fre- quently used room for the students who are studying in library of JNEC at night. This case study was done at night from 8pm to 10pm from14/07/20 to 21/07/20 for the duration of 7 days. LED bulb is being used in the washroom which has a power rating of 12 watt. The Energy consumption before the implementation of the system with 2 hours of light $\mathrm{ON}$ from $8 \mathrm{pm}$ to $10 \mathrm{pm}$ for 7 days was calculated to be $168 \mathrm{Watt}-\mathrm{hour}$. After the light was installed, the light was made to be ON only for 3 minutes whenever a person enters the washroom. Since this smart lighting will be used only when a person enters the washroom at night, the power consumption was drastically low with only 50.73 Watt-hour within 7 days as can be seen in the Figure 13.

TABLE 2 OBSERVATION TABLE FOR CASE STUDY FOR ENERGY EFFICIENCY

\begin{tabular}{|l|c|c|c|}
\hline Day & Number of usages & Delay time (hrs) & Total (Wh) \\
\hline Day 1(13/07) & 10 & 0.05 & 6.00 \\
\hline Day 2(14/07) & 16 & 0.05 & 9.33 \\
\hline Day 3(15/07) & 12 & 0.05 & 7.2 \\
\hline Day 4(16/07) & 11 & 0.05 & 6.6 \\
\hline Day 5(17/07) & 9 & 0.05 & 5.4 \\
\hline Day 6(18/07) & 12 & 0.05 & 7.2 \\
\hline Day7(20/07) & 15 & 0.05 & 9 \\
\hline
\end{tabular}

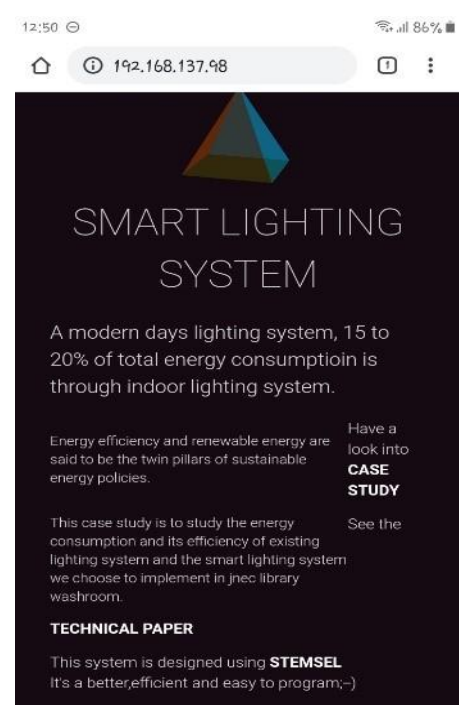

Fig. 10. Website of Smart Lighting System in mobile phone 


\section{International Advanced Research Journal in Science, Engineering and Technology}

Vol. 7, Issue 9, September 2020

\section{DOI 10.17148/IARJSET.2020.7908}

\section{CONCLUSION}

The paper is primarily about the improvement of current indoor lighting system by using smart processor and wireless actuator. It provides a model of a smart lighting to reduce the energy consumption automatically. From this paper, it is proved that the energy consumption can reduced by more than 50\% [23]. The faulty lamp can be known remotely with the help of zigbee. Since there won't be any data received at the control room if the light is working. Thus, the maintenance will be convenient. The work in particular has been a successful test on applications of sensors in lighting system. The future works could include the scaling upto building size deployment of these system. The adoption of this technology can be tried in urban area. Further more robust and reliable sensors which can be deployed in system to generate even more reliable data, perform monitoring and controlling can be explored. Smart lighting can be further mechanized for home automation products using modern emerging technologies. IoT technologies with smarter and more reliable sensors can be explored and expand in the future. With the advanced and more number of sensors implemented, the delay in the system can be compromised. Hence improving the efficiency and reliability of the system.

\section{REFERENCES}

[1]. A. K. N. X. a. S. K. P. Lwin Myo Thet, “A Smart Lighting System using Wireless Sensor,” in Intelligent Systems Conference 2017, Singapore, 7- 8 September 2017.

[2]. Han, Dae-Man, and Jae-Hyun Lim “Smart home energy management system using IEEE 802.15. 4 and zigbee."IEEE Transactions on Con- sumer Electronics56.3 (2010): 1403-1410.

[3]. A. P. S. Sanket Thakare, "The Internet of Things -Emerging Technolo- gies, Challenges and Applications," in International Journal of Computer Applications (0975 -8887), Mumbai, India, September 2016

[4]. Thet, Lwin Myo, et al. "A smart lighting system using wireless sen- $\quad$ sor actuator network."2017 Intelligent Systems Conference (IntelliSys). IEEE, 2017.

[5]. A. F. M. M. Lucio Ciabattoni, "A smart lighting system for industrial and domestic use," in Proceedings of the IEEE International Conference on Mechatronics (ICM), Vicenza, Italy, 2013.

[6]. D. A. M. Ms. M. Kokilavani, "Smart Street Lighting System using IoT," in International Journal of Advanced Research in Applied Science and Technology ISSN, Coimbatore, November 2017.

[7]. Parkash, Prabu V., and Dandu Rajendra. "Internet of things based intelligent street lighting system for smart city."International journal of innovative research in science, engineering and technology5.5 (2016).

[8]. Archana. G, Aishwarya N, Anitha J "Intelligent Street Light System” International Journal of Recent Advances in Engineering Technology, Vol3, Issue-4, 2015.

[9]. KapseSagar Sudhakar1, AbhaleAmol Anil2, Kudakechetan Ashok3, ShirsathShravan Bhaskar4 "Automatic Street Light Control System" International Journal of Emerging Technology and Advanced Engineer- ing"Volume 3, Issue 5, May 2013

[10]. R. K. Kodali, V. Jain, S. Bose and L. Boppana, "IoT based smart security and home automation system," 2016 International Conference on Computing, Communication and Automation (ICCCA), Noida, 2016, pp. 1286-1289, doi: 10.1109/CCAA.2016.7813916.

[11]. S. Kousalya, G. Priya, R. Vasanthi and B.Venkatesh, "IoT based Smart security and smart home automation," International Journal of Engineering Research Technology, Vol.7, Issue 4, 2018, pp.43-46

[12]. S. S. Chowdhury, S. Sarkar, S. Syamal, S. Sengupta and P. Nag, "IoT Based Smart Security and Home Automation System," 2019 IEEE 10th Annual Ubiquitous Computing, Electronics Mobile Communication Conference (UEMCON), New York City, NY, USA, 2019, pp. 1158- 1161, doi: 10.1109/UEMCON47517.2019.8992994.

[13]. B. R. A. K. R. Subramanym B.K, "Design and Development of Intelligent: Wireless Street Light Control and Monitoring System Along with GUT," International Journal of Engineering Research and Applica- tions(IJERA), vol. 3, no. 4, pp. 2115-2119, July-August 2013.

[14]. Schubert, E. Fred, and Jong Kyu Kim. "Solid-state light sources getting smart."Science308.5726 (2005): 1274-1278.

[15]. Margapuri, Venkat. ”Smart Motion Detection System using Raspberry Pi.”arXiv preprint arXiv:2006.06442(2020).

[16]. R. Jain, "Zigbee interfacing arduino," Arduino Zigbee tutorial, 14 feb 2019.

[17]. "DigiInternational," [Online] Available: https://www.digi/resources/examples-guides/map-your-digi-xbee-iot- network-digi-xctu. [Accessed 14 7 2020].

[18]. "XBee S2C-RF Module," $16 \quad 10$ 2018. [Online]. Available: https://components101.com/wireless/xbee-s2c-module-pimoutdatasheet:-:text=XBeeS2C. [Accessed 157 2020].

[19]. S. Mathew, "Zigbee Arduino Interfacing," 17 June 2015. [Online]. Available: https://www.mepits.com/210/communication/Zigbee.

[20]. R. Jain, "XBee Module Interfacing with Arduino," 14 Feburary 2019. [Online]. Available: https://circuitdigest.com/microcontrollerprojects/arduino-xbee-module-interfacing-tutorial. [Accessed 7 July 2020].

[21]. J. P. V. Anila Devi, "GSM Based Remote Control System of High Efficiency Intelligent Street Lighting System Using Zigbee Network of Devices and sensors," International Journal of Science and Research, pp. 2319-7064.

[22]. STEMSEL [online]. Available: https://www.stemsel.com[Accessedon June 12,2020]

[23]. K. N. Nithya P, "Design of Wireless Framework for Energy Efficient Street Light Automation," International Journal of Innovative Research in Computer and Communication Engineering, vol. 2, no. 1, 2014. 